\title{
Alternative Hydrogen Peroxide sources for Peroxyoxalate "Glowstick" Chemiluminescence Demonstrations
}

Iain A. Smellie,* Joanna K. D. Aldred (née Prentis), Benjamin Bower, Amber Cochrane, Laurie Macfarlane, Hollie B. McCarron, Roxana O'Hara, Iain L. J. Patterson, Marie I. Thomson and Jessica M. Walker.

*EaStChem, University of St Andrews, School of Chemistry, St Andrews, Fife, KY16 9ST, Scotland, United Kingdom.

Simple protocols have been devised for peroxyoxalate chemiluminescence demonstrations that use urea-hydrogen peroxide or sodium percarbonate as oxidants in place of aqueous solutions of hydrogen peroxide. The procedures described are compatible with well-known peroxyoxalates and fluorescers and have been found to be convenient for use for outreach activities in venues with limited laboratory facilities.

\section{ABSTRACT GRAPHIC}

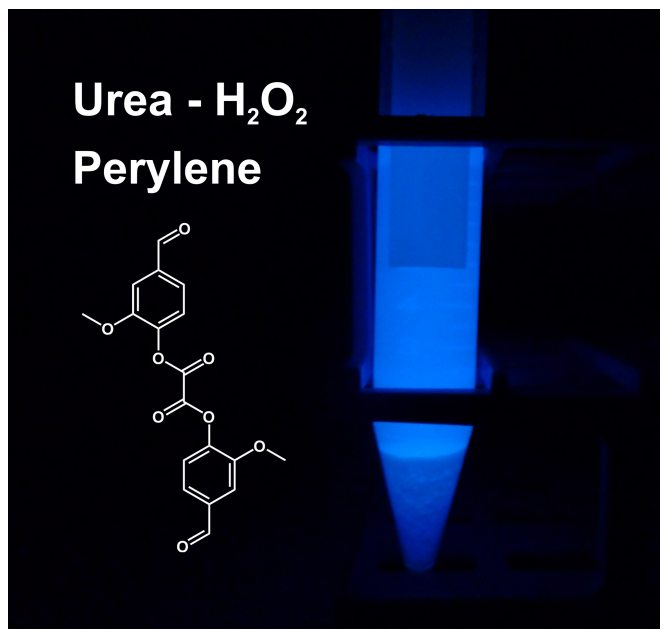

\section{KEYWORDS}

General Public, High School/ Introductory Chemistry, Demonstrations, Organic 


\section{INTRODUCTION}

Peroxyoxalate chemiluminescence ("glowstick") reactions are very popular in a variety of lecture demonstrations or teaching laboratory activities, indeed, they have been the subject of many publications in this journal since the initial discovery of the reaction. ${ }^{1-7}$ In a typical demonstration, a solution of a suitable oxalate diester and fluorescer in organic solvent is treated with aqueous hydrogen peroxide (depending on the identity of the oxalate diester, a base may also be added) to initiate chemiluminescence. The most frequently used oxalate diesters are bis $(2,4,6$ trichlorophenyl) oxalate (TCPO) and bis(2,4-nitrophenyl) oxalate (DNPO,). In recent years more environmentally benign analogues derived from vanillin (DVO) ${ }^{6}$ and methyl salicylate $(\mathrm{DMO})^{7}$ have successfully been introduced.

In this article we report a modification of the most common peroxyoxalate chemiluminescence protocols, where bench-stable solid hydrogen peroxide sources are used instead of aqueous hydrogen peroxide solutions in peroxyoxalate chemiluminescence reactions. Aqueous hydrogen peroxide solutions of concentrations of $30 \mathrm{wt} \%$ or less can be routinely manipulated safely, providing appropriate precautions are taken. However, hydrogen peroxide solutions decompose on storage and as a result, stocks usually require refrigeration if stored for long periods of time. Transportation of hydrogen peroxide solution requires care due to the possibility of spillage (especially in bottles with vented caps), aqueous solutions also have disadvantages in terms of their volume and weight. We sought bench-stable alternatives for use in outreach activities in venues that were off-campus and that had limited laboratory facilities. The ideal oxidant would be easily transported, conveniently stored and if possible, obtained from a grocery store. In this study, sodium percarbonate and urea hydrogen peroxide were selected as hydrogen peroxide sources for a 
chemiluminescence demonstration that involved making and activating a simplified "glowstick".

50<smiles>O=C(Oc1ccc([N+](=O)[O-])cc1[N+](=O)[O-])C(=O)Oc1ccc([N+](=O)[O-])cc1[N+](=O)[O-]</smiles><smiles>COc1cc(C=O)ccc1OC(=O)C(=O)Oc1ccc(C=O)cc1OC</smiles><smiles>O=C(Oc1c(Cl)cc(Cl)cc1Cl)C(=O)Oc1c(Cl)cc(Cl)cc1Cl</smiles>

TCPO<smiles>COC(=O)c1ccccc1OC(=O)C(=O)Oc1ccccc1C(=O)OC</smiles><smiles>O=C(Oc1c(Br)cc(Br)cc1Br)C(=O)Oc1c(Br)cc(Br)cc1Br</smiles>

$\mathrm{Na}_{2} \mathrm{CO}_{3} \cdot 1.5 \mathrm{H}_{2} \mathrm{O}_{2}$

Sodium Percarbonate<smiles>NC(N)=O</smiles>

\section{Urea hydrogen} peroxide

Figure 1 Oxalate diesters and hydrogen peroxide sources for chemiluminescence demonstrations.

55

\section{PROCEDURES}

The optimised protocols for chemiluminescent reactions involving solid hydrogen peroxide precursors are outlined in the following sections (full experimental details are provided in the supporting information document). In each case TBPO, DVO and DMO (figure 1) were treated with sodium percarbonate, fabric stain remover containing sodium percarbonate or urea-hydrogen peroxide. Rubrene and perylene were selected as fluorescers since they give strong emission of light, however there are potentially other options ${ }^{4}$ if different colours of light are desired. It was found that $15 \mathrm{~mL}$ polypropylene screw-cap centrifuge tubes were convenient reaction vessels because they were robust enough for transport and they allowed any carbon dioxide pressure buildup to be released quickly and easily. The tubes were also found to have the advantage that they could be re-sealed until ready for disposal. 


\section{Sodium Percarbonate Variants}

A centrifuge tube was charged with sodium percarbonate, fluorescer, and 0.003 M stock solution of peroxyoxalate in ethyl acetate. No reaction was observed until a small quantity of water was added and the resulting biphasic mixture was vigorously shaken. Light was emitted within a few seconds after addition of water (figure 2), over the course of a few minutes the glow began to fade, although further shaking led to further emission of light. In addition, the procedure was adapted to use commercially available fabric stain remover that contained sodium percarbonate. ${ }^{8}$

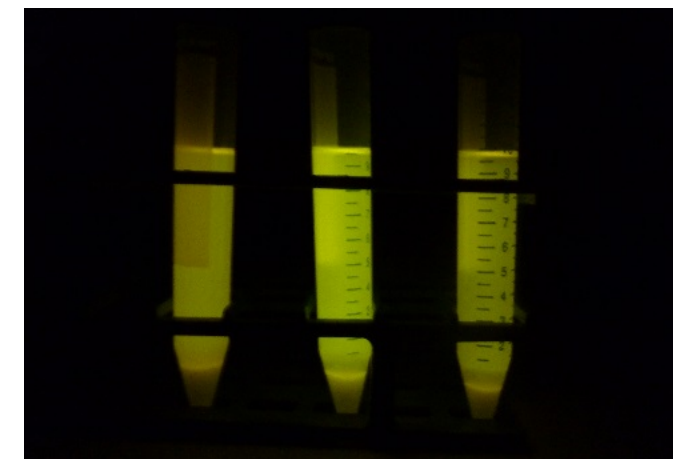

Figure 2 Example glowsticks with sodium percarbonate as oxidant are shown. In each tube, rubrene has been employed as the fluorescer and ethyl acetate solutions of TBPO, DVO and DMO (left to right) have been used.

\section{Urea Hydrogen Peroxide Variant}

A similar procedure to that above was employed, with urea hydrogen peroxide as the oxidant. A centrifuge tube was charged with urea hydrogen peroxide, fluorescer, and $0.003 \mathrm{M}$ stock solution of peroxyoxalate in ethyl acetate. No reaction was observed until a small quantity of sodium salicylate or sodium carbonate was added and the contents vigorously shaken, light was then emitted within a few seconds (figure 3). 


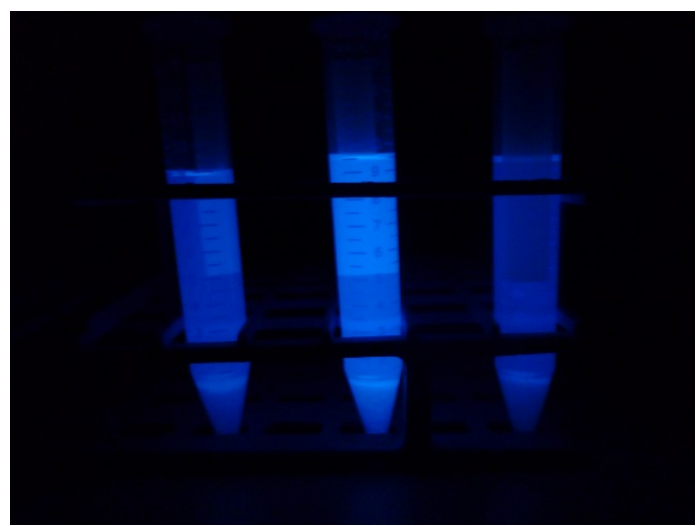

Figure 3 Example glowsticks with urea-hydrogen peroxide as oxidant are shown. In each tube, perylene has been employed as the fluorescer and ethyl acetate solutions of TBPO, DVO and DMO (left to right) have been used.

\section{HAZARDS}

A laboratory coat and safety glasses must be worn by the presenter and any participants. Do not allow any of the substances in use to come into contact with skin. Ethyl acetate should be considered flammable and harmful by inhalation, ingestion or skin absorption. Hydrogen peroxide sources should be considered corrosive and should not come into contact with skin or eyes. Hydrogen peroxide sources should not be exposed to acidic solutions containing oxidisable solvents (such as acetone). Polyaromatic hydrocarbon fluorescers are skin/eye irritants and are considered as potential carcinogens. All aqueous and organic wastes should be collected in appropriate containers for proper disposal.

\section{RESULTS AND DISCUSSION}

Early inspiration for these protocols came from an article on the use of peroxyoxalate chemiluminescence as a means of determining the hydrogen peroxide content of washing powders (where the hydrogen peroxide is usually present as sodium percarbonate). ${ }^{9}$ Subsequently, work conducted by Weiß et al came to our attention, ${ }^{10}$ in particular, an innovative procedure that involved grinding TCPO and commercially available sodium percarbonate mixtures in biodiesel to initiate chemiluminescence. Sodium percarbonate is certainly an attractive hydrogen peroxide source since it is a 
bench-stable solid, easy to manipulate and is inexpensive. A key advantage of this oxidant is wide availability in grocery stores due to its application in household laundry products. 8,10

The protocol reported herein was found to work well using sodium percarbonate from chemical suppliers and in laundry products. However, it was noted that in the latter case, the light emitted was not quite as intense as that emitted from mixtures containing sodium percarbonate sourced from chemical suppliers. It was also found that a slightly larger quantity of oxidant was required for optimum results, this observation is consistent with the lower proportion of sodium percarbonate in the laundry product used (iodometric titration results are outlined in the supporting information document). It has been reported that addition of a weak base to reactions mixtures containing TCPO leads to a marked increase in the reaction rate. ${ }^{3,11}$ In this procedure, additional base was found to be unnecessary since it is presumed that sodium carbonate is liberated on decomposition of sodium percarbonate in water.

Urea hydrogen peroxide has been reported as a convenient oxidant for a variety of functional group conversions and shares many attributes with sodium percarbonate in terms of ease of manipulation, storage and availability from chemical suppliers. ${ }^{12,13}$ Urea hydrogen peroxide may also be familiar to the general public due to its use in formulations of "over the counter" ear wax removers. ${ }^{14}$ Attempts to initiate chemiluminescence with urea hydrogen peroxide sourced from chemical suppliers were found to work well, even with oxidant that had been stored for more than four years. However, it was noted that the light generally faded faster using urea hydrogen peroxide than the procedures that used sodium percarbonate as the oxidant. In this variant of the procedure there is no species basic enough to facilitate the reaction, so it was found 
that addition of sodium salicylate or sodium carbonate was necessary. The latter additive has the advantage that it is cheap and available from grocery stores as washing soda. An attempt was also made to use a pharmaceutical formulation of urea hydrogen peroxide as the oxidant, however this was unsuccessful. This observation is perhaps unsurprising since oxidant content is typically low (ca. $5 \% \mathrm{w} / \mathrm{w}$ ) and additional additives are present.

In conclusion, sodium percarbonate and urea hydrogen peroxide have been found to be effective replacements for aqueous solutions of hydrogen peroxide in peroxyoxalate chemiluminescence demonstrations. The resulting protocols are simple and lend themselves to being safely transported. The revised procedure has also been found to be appropriate for demonstration venues where availability of laboratory equipment was minimal.

\section{ASSOCIATED CONTENT}

Demonstration protocols have been provided in the supporting information document. This material is available via the Internet at http://pubs.acs.org

\section{AUTHOR INFORMATION}

Corresponding Author

160 *I. A. Smellie. E-mail: ias10@st-and.ac.uk

\section{ACKNOWLEDGMENT}

The protocols described were developed and tested as part of the University of St Andrews CH3441 Mini Chemistry Project and ID4001 Communication and Teaching in Science modules. The authors would like to express their sincere thanks to the staff and students at Kingussie High School and Grove Academy for their help in testing the experiments. 


\section{REFERENCES}

(1) Mohan, A. G; Turro, N. J. A Soluble, A Facile and Effective Chemiluminescence Demonstration

(2) Shakhashiri, B. Z; Williams, L. G; Dirreen, G. E.; Francis, A. "Cool-light" Chemiluminescence. J. Chem. Educ. 1981, 58, 70-72.

(3) Hadd, A. G; Lehmpuhl, D. W; Kuck, L. R.; Birks, J. W. Chemiluminescence Demonstration Illustrating Prniciples of Ester Hydrolysis Reactions. J. Chem. Educ. 1999, 76, 1237-1240.

(4) Kuntzleman, T. S; Rohrer, K; Schultz, E. The Chemistry of Lightsticks: Demonstrations to Illustrate Chemical Processes. J. Chem. Educ. 2012, 89, 910-916.

(5) Wieczorek, R. R; Sommer, K. A Soluble, Demonstrating the Antioxidative Capacity of Substances with lightsticks. J. Chem. Educ. 2011, 88, 468-469.

(6) Jilani, O.; Donahue, T. M; Mitchell, M. O. A Greener Chemiluminescence Demonstration. J. Chem. Educ. 2011, 88, 786-787.

(7) Cambrea, L. R; Davis, M. C; Groshens, T. J.; Meylemans, H. A. A Soluble, Halogen-Free Oxalate from Methyl Salicylate for Chemiluminescence Demonstrations. J. Chem. Educ. 2013, 90, 1253-1254.

(8) Royal Society of Chemistry/Reckitt Benckiser "Chemistry in your Cupboard!" http://www.rsc.org/learn-chemistry/resources/chemistry-in-your-cupboard/vanish_accessed September 2016)

(9) Omanovic, E.; Kalcher, K. A New Chemiluminescence Sensor for Hydrogen Peroxide Determination. Int. J. of Environ. An. Ch. 2005, 85, 853-860.

(10) (a) For an excellent overview of chemiluminescence protocols with household materials see http://www.chemie.uni-jena.de/institute/oc/weiss/peroxyoxalat.htm (accessed September 2016);

(b) Brandl, H.; Weiß, D.; Albrecht, S.; Chemolumineszenz mit Haushaltschemikalien, Der Mathematisch Naturwissenschaftliche Unterricht, 2011, 64, 160-164

(11) Ciscato, L. F. M. L.; Augusto, F. A.; Weiss, D.; Bartoloni, F. H.; Albrecht, S.; Brandl, H.; Zimmermann, T.; Baader, W. J. The Chemiluminescent Peroxyoxalate System: State of the Art Almost 50 Years from its Discovery. Arkivoc. 2012, (iii), 391-430.

(12) Filipan-Litvic, M.; Litvic, M.; Vinkovic, V. An Efficient, Metal-free, Room Temperature Aromatization of Hantzsch-1,4-dihydropyridines with Urea-hydrogen Peroxide Adduct, Catalyzed by Molecular Iodine Tetrahedron, 2008, 64, 5649-5656.

(13) Varma, R. S.; Naicker, K. P. The Urea Hydrogen Peroxide Complex: Solid-State Oxidative Protocols for Hydroxylated Aldehydes and Ketones (Dakin Reaction), Nitriles, Sulfides, and Nitrogen Heterocycles Org. Lett, 1999, 1, 189-192.

(14) Hand, C; Harvey I. The effectiveness of topical preparations for the treatment of earwax: a systematic review. Br. J. Gen. Pract. 2004, 54, 862-867. 